\title{
Grandmas Project: memória e afeto na cozinha
}

\author{
Maria Leticia Mazzucchi Ferreira* \\ ORCID iD 0000-0003-3379-6378 \\ Universidade Federal de Pelotas, Departamento de Museologia, Conservação e Restauro, Pelotas, Brasil
}

Resumo: Neste artigo é proposta a análise de narrativas orais de mulheres idosas através do programa Grandmas Project, que consiste em filmes de 8 minutos feitos por netos junto às suas avós executando receitas que estejam associadas às suas trajetórias biográficas. No encontro intergeracional entre avós e netos se estabelece um diálogo no qual a memória atua tanto como a motivação de cada cinegrafista quanto como evocação para as idosas com suas receitas. Contextos históricos, tramas sociais, relaçóes com o tempo e com o próprio corpo formatam as lembranças narradas pelas avós, constituindo, assim, uma janela aberta para o passado que é ressignificado no presente. A cozinha, lugar de realizaçáo do vídeo, é também um lugar de memória, afeto e vida.

Palavras-chave: Grandmas Project. Culinária. Velhice. Memória. História Oral.

\section{Grandmas Project: memory and affection in the kitchen}

Abstract: In this article, oral narratives of older women participating of the Grandmas Project are analyzed, which consists of short films of eight minutes each produced by grandchildren together with their grandmothers, who prepare recipes associated with their life stories. In the intergenerational encounters between grandchildren and grandmothers a dialogue is established in which memory acts as a motivation for each filmmaker as well as an evocation for the older women in the revealing of their recipes. Historical and social contexts, relations with time and one's own body, all shape the memories narrated by the grandmothers, opening a window to the past which is given new meaning in the present. The kitchen, the site where the filming is conducted, is also a place of memory, affection and life.

Keywords: Grandmas Project. Cooking. Memory. Old age. Oral History.

Doutora em História pela Pontifícia Universidade Católica do Rio Grande do Sul (PUC-RS). Professora do Programa de Pós-Graduação em Memória Social e Patrimônio Cultural da Universidade Federal de Pelotas (UFPel). E-mail: leticiamazzucchi@gmail.com. 
Em entrevista concedida a Anne-Marie Granet-Abisset, Philippe Joutard recupera o que seria o marco de origem de seu interesse pelos relatos orais quando de sua pesquisa sobre o movimento dos Camisards, tema de tese de doutoramento defendido em 1974. Na entrevista, relata um momento específico, o feriado de Páscoa do ano 1966, transcorrido em sua casa na região de Cévennes, na França, e seu encontro com o pastor local, Paul Bastian, a quem credita seu reconhecimento da tradiçáo oral como um fio condutor do passado ao presente, em constante atualizaçáo. Assim, ele recupera os primeiros passos de sua trajetória em campo como um relato de surpreendentes descobertas:

Íamos a regiōes muitos distantes... Recordo-me bem de minhas duas ou três primeiras entrevistas. Em um primeiro momento, colocava perguntas bem precisas, mas, rapidamente, de maneira bastante empírica, voltei-me a entrevistas semidiretivas, pois me indagava se não induzia respostas e, particularmente, expressóes formidáveis, como 'ah, sim, essa história nós a sugamos com o leite de nossa mãe', 'os Camisards foram os cátaros do passado e os comunistas de hoje', sem falar de toda uma série de reflexóes. Era apaixonante, pois havia um tom emotivo, muito vivo, pessoal e visceral [...]. A história oral que eu descobria era interessante não apenas pelo que ela dizia, mas pela forma como se podia interpretar o que ela dizia, quer dizer, as aproximaçôes com outros períodos, como, por exemplo, os fenômenos de camisardisation, narrativas sobre elementos que não eram da guerra dos Camisards, mas ligados à resistência protestante durante a Segunda Guerra mundial. (Joutard, Granet-Abisset, 2013). ${ }^{1}$

A camisardisation, à qual se refere Joutard, bem poderia ser traduzida como essa memória de longa duraçáo que irrompe no presente sob a forma de narrativas, lendas, mitos, apropriaçôes sempre construídas em circunstâncias sociais determinadas. Mas, para além disso, e como nos deixa ver o próprio autor na recomposição que faz do momento original, é memória que se transmite "com o leite de nossa máe". Mais do que licença poética, esta expressão nos remete ao ato de transmissão conduzido aqui pelo fio da narrativa. A metáfora do fio conector simboliza, tal qual no mito de Ariadne, a possibilidade do retorno frente aos descaminhos labirínticos da memória, reduzindo a possibilidade do erro, garantindo o reconhecimento da impressão no bloco de cera, a memória feliz, como aponta Paul Ricoeur (2000). Entretanto, a possibilidade do

$1 \quad$ No original: "On allait dans des zones très reculées. Je me souviens bien de mes deux ou trois premiers entretiens. Dans un premier temps, j'avais posé des questions très précises et assez vite j’en suis venu - de manière très empirique - à des entretiens semi-directifs car je me demandais si je n'induisais pas les réponses et notamment ces expressions formidables : "Mais oui cette histoire, on l'a sucée avec le lait de notre mère!", "les Camisards c'était les Cathares d'autrefois et les communistes d'aujourd'bui ", ou sans parler de toute une série d'autres réflexions. C'était passionnant car il y avait un côté émouvant, très vivant, très personnel et charnel mais surtout pour moi, historien, c'était par les questions que ces récits suggéraient. L'histoire orale que je découvrais 
erro, a dimensão simbólica, interpretativa e igualmente ficcional das narrativas orais se coloca para o historiador como um desafio, mas, sobretudo, como uma potência, pois "os erros da memória são uma fonte de verdade", como afirma Philippe Joutard (1992), levando o pesquisador a buscar compreender a construção mesma dos relatos, o que neles é incorporado como lembrança e o que, ao náo ser evocado, constitui-se em esquecimento.

É pela imagem de um fio conectando dois polos, dois tempos, que se constrói o objeto deste artigo, a relação entre memória, história oral e envelhecimento, a partir da análise do Grandmas Project, idealizado pelo cineasta francês Jonas Parienté, em 2013. Inspirado nas histórias de suas avós, judia-egípcia pelo lado paterno e judia-polonesa pelo materno, ambas carregando consigo relatos de exílio para a França, nos anos 1950, Parienté evoca os pratos de sua infância, preparados pelas avós, como um lugar de convergência entre memória, identidade, permanências e rupturas em contextos migratórios. Em entrevista concedida ao canal France3, Jonas Parienté descreve o processo de constituição das filmagens que, longe de se constituírem como entrevistas, são interaçóes dinâmicas e afetivas entre um cineasta e sua avó. Em suas palavras: "a ideia é partir de uma receita de cozinha e desenrolar o fio: com quem aprendeu? Em qual contexto? a receita constitui-se numa narrativa a partir da qual muito rápido se chega a 'conte-me sua infância... como chegou na França?'”2

Parienté recupera sua experiência pessoal de neto de imigrantes, experiência reelaborada em uma situação igualmente migratória, quando passa a viver nos Estados Unidos, mas, sobretudo, a partir do nascimento do filho, como os fatores que o levaram à elaboração do projeto que se constitui como uma websérie colaborativa, envolvendo jovens cineastas de diversas partes do mundo com vídeos de 8 minutos feitos com suas avós executando receitas que fazem parte da memória familiar.

Ainda que o objeto deste artigo não se caracterize como uma experiência formal de pesquisa com o uso da História Oral, entende-se ser possível que, através dele, se possa compreender outras formas de apreensão dos relatos orais. No Grandmas Project, o elemento ativador de tais relatos é a execuçáo de uma receita culinária, a expectativa do compartilhamento do que lentamente se origina dos ingredientes e dos relatos.

$\mathrm{O}$ agente da filmagem (netos, netas) procede a uma experiência do questionamento, da busca de índices, do desconhecido do qual, paradoxalmente, também faz parte. As narrativas orais apresentam a função de um instrumento de conhecimento (de quem registra) e de reconhecimento (do narrador). No processo de filmagem das avós, não estiveram presentes instrumentos tradicionais de abordagem na pesquisa de História

ainsi était intéressante non seulement par ce quelle disait mais par la manière dont il fallait interpréter ce quelle disait, c'est-à-dire les rapprochements, avec d'autres périodes, comme, par exemple, les phénomènes de camisardisation, c’est-à-dire des récits sur des éléments qui nétaient pas de la guerre des Camisards mais liés à la résistance protestante durant la Seconde Guerre mondiale" (livre tradução da autora).

2 Disponível em: https://fb.watch/5_rsHSfjpP/. Acesso em: 7 jun. 2021. 
Oral, como o roteiro de entrevista, as técnicas de abordagem do entrevistado e o diário de campo, que se constituem em importantes meios de recuperar os traços "invisíveis/ inaudíveis" da entrevista. Entretanto, no encontro informal e familiar entre netos e avós, percebem-se os contornos do diálogo entre "entrevistador e entrevistado", em que "os papéis se modificam, mudam, nem sempre é o entrevistador quem faz as perguntas, há perguntas colocadas pelo entrevistado" (Portelli, 2010), entendendo-se a ligação de reciprocidade que se instaura entre ambos: o reconhecimento da singularidade de sua vida, por parte de quem narra, e a busca pelo "alargamento do campo, pela contextualização do testemunho" (Bordin; Casellato, 2020), por parte de quem se coloca na posição do ativador memorial.

\section{Grandmas Project: lembrar, cozinhar, narrar}

O programa lançado por Jonas Parienté pode ser descrito como uma experiência entre indivíduos marcados pela semelhança - a mesma procedência familiar - e pela singularidade de seus papeis sociais e distâncias geracionais. O território simbólico no qual ocorre o encontro é o da memória familiar que é, conforme Anne Muxel (1996), ao mesmo tempo, o conjunto de registros e narrativas que atuam como força de coesão do grupo e, na perspectiva do sujeito, vivida como uma experiência pessoal. Ambos, grupo e sujeito, refletem as distintas dimensóes que atuam como enquadramento da memória e das narrativas orais que dela são geradas, quais sejam as transformaçóes sociais e históricas que presidem cada momento e a permanência de referências que se constituem como quadros estáveis no interior das trajetórias pessoais.

Por conta dessa característica, em 2016, o projeto recebeu patrocínio da Unesco, que reconheceu a pertinência do mesmo com base nos princípios da Convenção de Salvaguarda do Patrimônio Cultural Imaterial de 2003. Na justificativa do patrocínio, é ressaltado o papel das receitas executadas pelas idosas como testemunhos que "incarnam, de maneira íntima e deliciosa, as grandes transformaçóes do século XX: a Segunda Guerra Mundial, a descolonização, o feminismo, completando-se com a operação de coleta e registro dessas experiências pela geração dos netos, que são levados a interrogar e dialogar com essa história e dela se reapropriar". ${ }^{3}$

Foram analisados 5 dos 12 episódios disponíveis na primeira temporada do projeto, ${ }^{4}$ obedecendo ao critério de serem idosas que trazem um histórico de migração

3 Disponível em: https://www.chaireunesco-adm.com/Jonas-Pariente. Acesso em: 7 jun. 2021.

4 Os episódios foram produzidos entre 2015 e 2018, porém, parte deles não precisa o ano. Optou-se, nesses casos, por utilizar o ano de 2018. 
familiar. Em primeiro plano, está o nome de cada receita preparada: Marillenknödel por Suzanne Achache-Wiznitzer, 87 anos, filmada por Mona Achache, França-Áustria; Chouchouka por Ninette Zagury, filmada por Elsa Lévy, França-Marrocos; Kneidler por Julia Wallach, 93 anos, filmada por Frankie Wallach, França-Polônia; Mehchi por Rosa Maluf Milan, 97 anos, filmada por Mathias Mangin, Líbano-Brasil; Molokheya por Suzi Parienté (Nano), 83 anos, filmada por Jonas Parienté, França-Egito.

\section{“O outono e o inverno da vida são tão longos quanto a primavera e 0 verão" 5}

É com essa reflexão que Sonia Debeauvais (2018) nascida em 1924, na Dinamarca, encerra a filmagem feita por sua neta. $\mathrm{Na}$ estreita cozinha do antigo apartamento parisiense, essa nonagenária, falecida dois anos após a realização do vídeo, questionase sobre a própria ideia do tempo da vida, a juventude e a velhice que, mensuradas cronologicamente, são iguais em termos de unidades, mas apreendidas e vividas de forma diferente. A ideia de duração, na perspectiva de um fluxo percebido como um continuum sem rupturas, é um dos princípios da teoria de Henri Bergson (2011) sobre o tempo, e definida por ele como "a duração real é o que sempre foi chamado de tempo, mas o tempo percebido como indivisível", 6 ou seja, a percepção da vida interior náo corresponde a um tempo fracionado em anos, meses, horas, mas a um fluxo ininterrupto no qual as mudanças são vivenciadas não como descontinuidades, mas como uma sucessáo de estados interiores. Essa perspectiva do tempo subjetivo, não fracionado nem espacializado, fundamenta a ideia da continuidade, porém, tal como no pensamento expresso pela idosa, "o inverno é muito, muito longo, sobretudo quando se é velho", e dessa afirmação se pode depreender a representação de um tempo longo de declínio, um tempo que se dilata em um futuro sem projetos, sem um objetivo definido, tal como revela em sua entrevista (Sonia Debeauvais, 2018).

A evocação das estações do ano como representaçóes das idades da vida colocam o outono como um prelúdio ao inverno, estação de dias curtos, sombrios, propícios ao recolhimento, metáfora da velhice como uma fase de poucos objetivos e maior desgaste do corpo, tal como nos apresenta a protagonista. A relaçáo que estabelecemos com o tempo transita entre uma racionalidade linear, posto que externamente somos aferidos por cômputos de anos vividos, e outra tendendo a uma espiral, ou à ideia de um rio que

5 No original: "L'automne et l'biver de la vie sont aussi longs que le printemps et l'été" (livre tradução da autora).

6 No original: "Durée réelle est ce que l’on a toujours appelé le temps, mais le temps perçu comme indivisible" (livre tradução da autora). 
corre sem ater-se às transformaçóes no entorno.

Todas as mulheres filmadas por seus netos ou netas, dentro do quadro do Grandmas Project, estáo em faixa etária acima dos 80 anos no momento da filmagem. Como representar essa fase da vida? Com quais descritores podemos defini-la? Qual léxico deve ser utilizado para nomeá-la?

Se considerarmos os gráficos estatísticos sobre o envelhecimento populacional, verifica-se que o aumento da populaçáo mundial acima dos 60 anos cresce exponencialmente, demonstrando uma tendência de longevidade em quase todos os continentes. Dados da Organização Mundial de Saúde (OMS) indicavam que, em 2020, o número de pessoas com 60 anos ou mais seria superior ao de crianças com menos de cinco anos e que, em 2050, $80 \%$ das pessoas idosas viveriam em países de baixa e média renda, ou seja, países em desenvolvimento ou pouco desenvolvidos, ${ }^{7}$ totalizando cifra acima de 2 bilhóes de pessoas, algo em torno de $30 \%$ da população mundial. No Brasil, a população de maiores de 65 anos ficará entre os $25-30 \%,{ }^{8}$ configurando imenso contraste com a expectativa de vida do brasileiro ao nascer, que, em 1940, era de 41,5 anos e 51,6 anos, em 1960 (Berquó; Baeninger, 2000).

Entretanto, ainda que os dados demográficos apontem para uma maior expectativa de vida da populaçấo mundial, tal processo apresenta-se heterogêneo, uma vez que envolve diferentes fatores que condicionam um bem viver e, logo, um bem envelhecer. Tais fatores relacionam-se às condiçóes de vida, às políticas governamentais visando à populaçáo idosa, mas também às formas de compreensáo cultural e ao enquadramento social do envelhecimento.

Assim, se podemos estabelecer numericamente categorias de longevidade, como Terceira e Quarta idade, tais categorias não podem ser vistas como dados absolutos, pois náo podem dar conta da complexidade com a qual se reveste nossa relaçáo com o tempo da vida, tampouco com as condiçóes sociais e culturais que incidem diretamente sobre cada pessoa. Impóem-se, cada vez mais, dificuldades em dimensionar um período longo da existência - a lógica das quatro estaçóes da senhora Debeauvais - em categorias que buscam a homogeneidade e regularidade em seu interior.

Assim, como definir a velhice e, por consequência, como definir o recorte temporal exato que nela nos insere? Sem aderir ao discurso totalizante dos dados estatísticos ou mesmo das premissas biológicas, somos levados a pensar a velhice utilizando-nos do mesmo princípio de Pierre Bourdieu, ao afirmar que a "juventude é apenas uma palavra", ou seja, por um "abuso de linguagem” tende-se a subsumir, sob o mesmo conceito, universos sociais que praticamente não apresentam nada em comum (Mauger, 2001). Ao formular categorias semânticas que buscam dar conta de estados

7 Disponível em: https://www.who.int/fr/news-room/fact-sheets/detail/ageing-and-health. Acesso em: 8 jun. 2021.

8 Disponível em: https://population.un.org/wpp/Maps/. Acesso em: 8 jun. 2021. 
da vida, somos igualmente condicionados a constantemente atualizá-las, tendo em vista que tais categorias se colocam como referenciais normativos formulados no interior da cultura e de políticas públicas que incidem sobre tais referenciais. Dessa forma, numa sociedade regulada pela lógica da produção e modulação do tempo vivido para o trabalho, a aposentadoria foi considerada, entre os anos 1960 e 1970, o marco inicial da "terceira idade", fase que antecederia uma velhice dependente (Caradec, 2008). Tais referenciais vêm sendo colocados em questáo, já que, cada vez mais, a aposentadoria não indica necessariamente uma desconexão do sujeito do mundo do trabalho, seja por imposição de obter maiores recursos, em razão de benefício insuficiente, seja pelo próprio emprego do tempo em outras atividades, não necessariamente remuneradas. Da mesma forma, nem todos os idosos acima de 80 anos apresentam condições de saúde física e mental debilitadas, o que levaria a um progressivo estado de dependência (Caradec, 2008).

Os vídeos que compóem o Grandmas Project apresentam um encontro entre avós e netos no interior de uma relação intergeracional em que a memória familiar, tanto de um lado quanto do outro, é o elemento que preside as escolhas feitas e atua como conector entre os dois sujeitos.

\section{"A casa do fogo": encontros na cozinha}

$\mathrm{Na}$ imagem que me vem à mente quando penso em minhas tias-avós, elas estão na cozinha que ficava ao final de um corredor muito longo, para mim que era criança. Era uma cozinha grande, mas um pouco escura, e elas estavam sempre lá, na beira do fogáo mexendo um tacho com doce, na ponta da mesa anotando alguma encomenda... elas tinham as costas arqueadas, e o perfume que sinto até hoje é do açúcar cozinhando na calda (Maria Alice Coelho Muccilo, sobrinha-neta das "irmãs Cordeiro", 2007). ${ }^{9}$

$\mathrm{Na}$ citação acima, o espaço aparece formatando a recordação. Um espaço no interior da casa, ela própria como moldura de uma memória afetiva. É em Maurice Halbwachs que o espaço, assim como o tempo, constituem molduras da memória que se produz no momento presente dos indivíduos. Nenhuma lembrança se concretiza fora de marcos dispostos pela sociedade, fora da interação com os outros seres sociais e fora de marcos espaciais. $\mathrm{O}$ espaço fornece regularidade e estabilidade às lembranças,

9 Entrevista realizada em 14/02/2007 pelo Inventário Nacional de Referências Culturais (INRC) Tradições doceiras de Pelotas e Antiga Pelotas. Essa entrevista faz parte do material do Inventário, mas ainda não foi publicada. 
espaço compreendido por ele tanto no sentido material quanto simbólico. Quando os membros de um grupo se dispersam, é o pensamento comum associado aos lugares coletivamente vividos que faz com que "permaneçam unidos através do espaço"10 (Halbwachs, 1997, p. 196). O espaço agencia o sentimento de imutabilidade e orientação nas mudanças que se colocam no curso da vida, e configura-se na trama das relaçóes entre os indivíduos de um grupo. O quadro espacial que formata as memórias gastronômicas, em geral, é constituído pela cozinha doméstica e, no caso em análise, pela cozinha das avós. São cozinhas funcionais, seja em uma casa em zona rural, seja num apartamento antigo ou mesmo em apartamentos modernos, cujos mobiliários oscilam entre o básico para preparo e acondicionamento de alimentos, até espaços mais amplos, contando com equipamentos mais sofisticados. Estar na cozinha, no contexto do programa, é mais do que tudo um registro do encontro memorial, e essa é a linha que conduziu a leitura dos vídeos realizados, para fins deste artigo.

A cozinha como um lugar de criação apresenta um grande espectro de estímulos sensoriais, tais como os odores, as sensaçóes táteis, os gostos. Nesse local, as idosas se deslocam, ora com agilidade, demonstrando o pleno domínio das atividades inerentes ao fazer culinário, ora com as dificuldades que o corpo longevo impóe. Antigas e biográficas, modernas e funcionais, cada cozinha pode ser analisada como um microcosmo no qual o tempo da vida transcorre no ritmo das tarefas cotidianas, mas também dos resíduos de memória que ali permanecem. A cozinha é, por excelência, o lugar das práticas ordinárias moduladas por um tempo "indefinidamente repetido da vida comum” (Certeau, 1996) no qual gestos, objetos e espaços participam e refletem elementos de uma ordem social e cultural, experenciada pelos sujeitos em suas singularidades. Nessa perspectiva, Meah e Jackson (2016) analisam como as memórias são mobilizadas neste espaço doméstico - espécie de zona de contato entre a dimensão íntima e privada com a pública e mundana da casa. Assim, objetos, odores e outros elementos sensoriais configuram "uma complexa topografia da vida doméstica" e "um repositório para a memória e nostalgia", convertendo-se em "lugares de memória" que, se, por um lado, interrogam o sentido da memória como elemento fundante da identidade nacional no sentido proposto por Pierre Nora, por outro, remetem-na ao interior da experiência vivida informada por categorias, como classe social, gênero, etnicidade e família, individualmente mais relevantes do que a identidade nacional (Meah; Jackson, 2016 ).

No Grandmas Project, as filmagens ocorrem nas cozinhas domésticas e ali as avós circulam, separam e misturam ingredientes, executando receitas que se vinculam a memórias familiares. "Se você preparar pratos como os de minha avó, certamente ficarei feliz": com essa frase, François Mitterand recebe sua nova cozinheira, Hortense Laborie, no Palácio do Eliseu, no filme Les saveurs du Palais (2012). Inspirado na

No original: "ils restent unis à travers l'espace" (livre tradução da autora). 
trajetória de Danièle Mazet-Delpeuch, primeira mulher chefe de cozinha na residência presidencial, a evocação feita pelo personagem à nostalgia da comida preparada pela avó, ainda que como retórica ficcional, tem fundamento na própria conformação e consolidação da memória olfativa, modalidade memorial que mais se aproxima das sensaçóes e registros afetivos. Em uma pesquisa realizada por Joël Candau, entre os anos 1996 e 1999, com 503 estudantes da Universidade de Nice, com o objetivo de aferir quais memórias olfativas eram evocadas espontaneamente, obteve-se uma taxa de $85 \%$ das respostas remetendo a lembranças olfativas agradáveis, vinculadas à infância e à família (odores e perfumes de pais e avós, casa familiar, refeiçôes dominicais, doces, etc.). Tais lembranças, como afirma o autor, são como impressóes que se conservam ao longo de nossa existência (Candau; Ferreira, 2015), estabelecem laços com o tratamento afetivo da informação e, por essa razão, estão fortemente associadas à codificação da memória e ao ato evocativo.

\section{Grandmas... entre receitas e lembranças}

\section{Marillenknödel}

Os knödel são bolinhos feitos com massa de batata cozida recheada com damasco, dentro dos quais se coloca um cubo de açúcar, e cozidos em água fervente. Quem executa a receita é Suzanne Achache-Wiznitzer, nascida em 1929, em Viena. Em sua pequena biografia, lê-se:

Eu viajei através do século e da Europa, é difícil encurtar! Minha mãe era uma mulher escandalosa. Ela ia a cafés, jogava cartas por dinheiro e perdia constantemente o que tinha. Ela morreu de câncer em 1937 e foi enterrada em Viena. Em 1938, parti para a França. Meu pai e meu irmão foram deportados em 1942. Por acaso, conheci Madame Chesneau, ${ }^{11}$ que estava abrindo a porta para todas as crianças com as quais não sabiam o que fazer e no final da guerra fiquei um ano com ela. (Suzanne Achache-Wiznitzer, 2017).

A filmagem inicia com uma tomada do rosto de Suzanne em primeiro plano e com a frase proferida por ela e atribuída a De Gaulle, dizendo que "a velhice é um naufrágio" 12 no sentido de que "não se tem mais atividade profissional, já se fez o que se

11 Suzanne Achache-Wiznitzer é uma testemunha das "crianças escondidas", filhos de deportados durante o período de perseguição nazista que, sobretudo na França, tiveram acolhimento em escolas internas, casas de família ou outros locais destinados a cumprir o papel de "substitutos dos pais" que, na maior parte dos casos, jamais regressaram dos campos de morte (Achache-Wiznitzer, 1993).

12 No original: "la vieillesse est un naufrage" (livre tradução da autora). 
tinha de fazer, se perde economicamente, se perde a força. É sobreviver por sobreviver, e quando o prazer de sobreviver se torna nulo, morremos silenciosamente" (Suzanne Achache-Wiznitzer, 2017).

Suzanne é médica, já afastada da atividade profissional; a forma como lida com os objetos e o preparo da receita revela um passado no qual as mãos estiveram longe dos afazeres próprios de uma cozinha. De suas habilidades culinárias, que deixa antever como muito precárias: "ah tem dois ou três pratos que sei fazer... o cuscuz de minha sogra, e eu sei fazer bem... sei vagamente fazer carpa à la juive, mas ninguém gosta, sobretudo meus filhos... e eu renunciei definitivamente a isso... faço o cuscuz, que não é de minha religião" (Suzanne Achache-Wiznitzer, 2017).13

Após o término do preparo dos Marillenknödel, enquanto fuma um cigarro, Suzanne reflete sobre nunca ter feito pratos da culinária austríaca para seus filhos, lamentando que assim eles nunca tenham podido apreciá-la. Percebe-se aqui que a noção de "culinária austríaca" aparece como elo perdido com um passado marcado pela história de uma família judia envolta, como tantas outras, na tragédia da deportação.

Ao término da filmagem, é do beijo dado pela neta que parece vir um tom mais esperançoso, "isso, tu vês, são dez anos de vida que tu me dás" (Suzanne AchacheWiznitzer, 2017).

O encontro entre duas geraçôes, uma cujo tempo passado se faz sentir no corpo e na relaçáo com o presente e outra, que do presente faz buscar esses vestígios vívidos do passado. Se o marco geracional as separa no tempo, as aproxima, ao final, em afeto.

Chouchouka (salada cozida)

Salada contendo pimentóes congelados, tomates, alho, pimenta, azeite, ingredientes marinados e cozidos lentamente. A receita é executada por Ninette Zagury, nascida em Casablanca e vivendo em Paris. Embora não cozinhe mais, ela ofertou aos netos um caderno com várias receitas exóticas: chouchouka, dafina, makhzina (Ninette Zagury, 2018).

Na cena, a neta folheia o caderno de receitas no qual há vários títulos em espanhol, "dos judeus da Espanha", como afirma Ninette. A câmera filma suas mãos picando o alho e vertendo um pacote de pimentóes congelados e tomates em lata dentro da panela sobre o fogão. À observaçáo feita pela neta em relação aos pimentốes congelados como desvios da receita original, Ninette afirma que "faz muito tempo que uso assim, são melhores". Enquanto a lente desliza pelo balcão da área de trabalho da cozinha, vemos objetos prosaicos, como uma panela com marcas de uso, um pano de prato sobre o qual repousam talheres e louças depois de lavadas, um cenário que pouco indica uma atividade mais intensa de preparo de alimentos.

13 No original: "Ça tu vois, c'est 10 ans de vie que tu me donnes" (livre tradução da autora). 
- Não cozinhas mais? pergunta a neta.

- Não.

- E isso não te faz falta?

- Não, pois não é prático, eu enjoei.

- E o gosto, o paladar, disso náo sentes falta? insiste a neta, ao que Ninette responde:

“o paladar, claro...eu esqueci...virei a página” (Ninette Zagury, 2018).

Ao declarar ter abdicado desse passado, "virar a página”, no sentido de constatar que a vida no presente já não comporta aquilo que um dia foi sua paixão - a cozinha -, Ninette estabelece essa renúncia como a fronteira entre um tempo e outro. Sem lamentar, reconhece não ter havido a transmissão do saber-fazer culinário à filha, "que nunca quis aprender e agora é muito tarde" (Ninette Zagury, 2018).

As páginas de um caderno de receitas de Ninette são desfolhadas frente à câmera, possibilitando, pela simples leitura dos títulos e ingredientes, avistar-se a cozinha mediterrânea na qual ela aprendeu alguns segredos da culinária marroquina, que remete às feiras nas quais produtos como azeites, pimentóes, canela, laranjas, açafrão são elementos culturais vivos, contrastando com a receita de Chouchouka na qual se lê que os pimentóes são Chez Picard, franquia de produtos congelados que existe em toda a França, vista como o oposto da boa e lenta cozinha tradicional. Entre o passado e o presente, que se apresenta mais largo, em razão de menos ocupaçóes, e paradoxalmente mais curto, pelo irreversível envelhecimento, a Chouchouka adaptada, preparada por Ninette, se coloca como uma atitude libertária, sem lamentos.

\section{Kneidler}

Receita da gastronomia judaica da Europa do Leste, feita com frango e vegetais que formam um cozido no qual são inseridos as matzo balls, espécie de almôndegas de farinha e ovo, cozidas na água fervente.

O filme inicia com Julia, "mammy d'amour", como informa a neta, circulando pelo apartamento. Em tomadas rápidas, vemos objetos pessoais, como um par de chinelos de inverno, um pote com instrumentos, como pinças e tesouras, outro com cosméticos, pentes e escovas de cabelo sobre a bancada do banheiro, perfumes, espelhos, o batom que Julia passa sobre os lábios, elementos indicadores de uma vaidade ainda vibrante. Em tomadas seguintes, a vemos já com um avental de cozinha com a inscrição Yiddish mamma, remetendo à sua origem judaica. A receita, tal como um símbolo dessa judaicidade viva, é apresentada pela neta em segundo plano dizendo que o Kneidler é para ela uma espécie de passaporte askhenazi.

Julia, tal como apresentada pela neta, é "uma super avó de 93 anos. Ela é uma sobrevivente do Holocausto. Nós rimos, bebemos, conversamos, fofocamos, mas também brigamos como duas melhores amigas".

Julia inicia o preparo da receita descascando os legumes com uma faca. Tal gesto, aparentemente banal, se revela como um hábito adquirido num local de sofrimento, 
o campo de concentraçáo. $\mathrm{Na}$ fala de Julia: "no campo eu trabalhei por dois meses na cozinha descascando cestas de batatas e ali aprendi a usar uma faca para fazer isso" (Julia Wallach, 2018).

A vivência em Auschwitz é abordada por Julia de forma menos trágica, como uma memória traumática que, como forma de sobrevivência, precisou ser ressignificada. $\mathrm{O}$ campo atravessa a narrativa dessa mulher, está no ato de retirar a casca dos legumes, na pergunta que faz à neta se não filmará seu número inscrito na pele do braço, "pouco visível", nas palavras da neta, "digamos que ele está enrugado, ele é velho", afirma Julia em tom de jocosidade, ou entáo ao se remeter ao cabelo que estaria ruim:

[...] antes eu tinha um cabelo bom, eu tenho uma foto de quando era pequena, eu creio que tinha seis anos, o cabelo era todo ondulado, mas eu acho que foi o campo que estragou meu cabelo. Eu tinha o cabelo ondulado, me rasparam a cabeça e um ano após eu tive tifo e tive que ter o cabelo raspado de novo. As minhas companheiras diziam 'deixa rasparem teu cabelo que depois ele vem bonito'; rasparam duas vezes, mas a terceira eu náo deixei e agora eles estáo crespos assim. (Julia Wallach, 2018).

Igualmente, as recordaçóes são ativadas pelo ato de preparar um prato que faz alusão a sua origem polonesa e às severas condiçóes de vida naquele país: "Eu não sei como era na França, mas, na Polônia, se era pobre e se economizava tudo para o Shabbat, tudo que era necessário, se vestir bem, tudo, tudo, o terno tinha que estar bem limpo, o sheteil, a peruca, tudo tinha que estar limpo, tudo novo" (Julia Wallach, 2018).

A guerra e as vivências que se associaram a ela aparecem como lembranças que explicam o presente, tal como o aprendizado da língua inglesa. "Eu aprendi inglês com os soldados americanos... eu tinha liçóes, um teacher" (Julia Wallach, 2018).

No preparo do Kneidler, revela-se uma história pessoal que, tal como afirma Halbwachs (1997), encontra eco nas tramas sociais. Remetendo-se às origens familiares, ${ }^{14}$ Julia evoca a vida de uma família judia pobre na Polônia antes da Segunda Guerra, as condiçóes difíceis que não impediam, porém o pleno cumprimento dos rituais religiosos, eixo fundamental da dignidade e identidade, a deportação para Auschwitz, destino mortal de mais de um milhão de judeus, as condiçóes da vida no campo de extermínio pautadas pela doença (o tifo que acomete Julia, uma adolescente de 18 anos), por privaçóes de todas as ordens, por humilhaçóes, pelo horror e aniquilamento da integridade psíquica, moral e física do internado. Essa marca indelével de uma vida

14 Julia Kac,nome de solteira. Nascida em 14/06/1925,em Paris,deportada em 23/06/1943 para Auschwitz. Disponível em: https://ressources.memorialdelashoah.org/notice.php?q=fulltext $\% 3 \mathrm{~A} \% 28 \mathrm{Julia} \% 20$ Wallach\%29\%20AND\%20id_pers\%3A\%28\%2A\%29\&start=1\&rows=1\&from=resultat\&sort_ define=\&sort_order=\&rows=. Acesso em: 7 jun. 2021. 
brutalmente sequestrada de seu curso imaginado aparece no número tatuado no braço, registro que acompanha toda uma vida, imiscuindo-se com as marcas do tempo que enrugam a pele, evocaçóes de um tempo de sofrimento extremo ${ }^{15}$ que culmina no retorno à Paris e no convívio com os soldados americanos.

O filme é concluído à mesa, como os demais programas. A mesa como o lugar do encontro, das memórias familiares. Aqui, conclui-se com um brinde dizendo lehaim, que em hebraico significa "à vida”.

\section{Mehchi}

Receita tradicional da culinária libanesa e executada por Rosa Maluf Milan, ${ }^{16}$ recebeu, no Brasil, o nome de Charutinho, podendo ser feito com repolho ou com folhas da videira, tal como preparado por Rosa. Os ingredientes são folhas de videira, carne bovina picada, arroz branco, tomates, pimenta síria, azeite de oliva. As folhas são passadas pela água fervente para que possam se tornar maleáveis ao enrolar a mistura da carne com os demais ingredientes e, depois de enrolados, os Mehchi cozinham por duas horas.

O ingresso no mundo de Rosa se dá pela imagem do céu que se vislumbra a partir da janela de seu quarto. A câmera desliza por entre as peças de um grande apartamento, móveis antigos e vistosos que informam a condiçáo abastada dos moradores: fotografias de família, um piano de cauda, um oratório em peça ao final de um longo corredor, um relógio de coluna antigo que adorna a mesma cena, na qual aparece, andando com dificuldade, Dona Rosa, anunciada pelo neto como sua avó de 97 anos, nascida no Brasil, de família libanesa, ${ }^{17}$ e cujas receitas, para ele, que vive na França, ainda que de origem libanesas, evocam o Brasil.

Na cozinha, Dona Rosa retira os anéis das mãos envelhecidas, preparando-se para iniciar a receita. Com destreza, manipula as folhas de videira que são enroladas com a carne. A relaçáo de Rosa com o preparo de pratos se revela dentro dos moldes de uma família libanesa com forte tradição culinária, mas também com memórias que remetem ao sofrimento, como a figura da cozinheira da casa de infância, a Hani, que impedia o acesso das meninas à cozinha. "Eu não gostava dela, ela era estúpida comigo e com minha irmá, ela só gostava dos meninos" (Rosa Maluf Milan, 2015). O traço cultural de uma sociedade de prevalência da figura masculina aparece igualmente na fala de Rosa, ao afirmar que ela também prefere os homens, ainda que só tenha tido filhas mulheres: "porque Deus não quis... tive o primeiro filho, mas perdi" (Rosa Maluf

15 Disponível em: http://rescapesdelashoah.org/julia-wallach/. Acesso em: 8 jun. 2021.

16 Rosa Milan, nascida em 1917, em uma família de origem libanesa, encontrou no trabalho uma forma de enfrentar a morte de seu amado marido, aos 48 anos (Rosa Maluf Milan, 2015).

17 Alguns elementos culturais da imigração síria e libanesa em São Paulo podem ser encontrados em referências como Oswaldo Truzzi $(1997,2008)$ e Marcia Maria Cabreira (2001). 
Milan, 2015).

No processo de transmissão dos saberes culinários, a tradição "árabe-libanesa”, como ela identifica, a figura de sua avó aparece como a que proporcionou sua introdução ao mundo da cozinha: "eu aprendi com minha avó... sentava na cozinha, num banquinho e ficava vendo o que ela fazia... minha avó, Azize, que era uma doçura de avó, eu adorava ela" (Rosa Maluf Milan, 2015). Numa perspectiva intergeracional, a relação de afeto com a avó, intermediada pela comida, reaparece no neto que, ao abrir a filmagem com Rosa, informa que sua memória de infância vem associada aos pratos preparados por ela.

Ao término da refeição com os Mehchi, Dona Rosa recosta-se no sofá e fecha os olhos, mergulhando talvez em recordaçóes de tantos outros momentos da convivialidade que possibilitavam as receitas preparadas por ela, no espírito de uma mulher que se impóe numa sociedade na qual não estava predestinada a fazê-lo.

\section{Molokheya}

Receita de origem egípcia, executada por Suzi Parienté, tendo como ingredientes principais carne (chuck) e folhas de molokheya, erva verde amarga, que, juntamente com outros temperos e ingredientes, resultam em um cozido de alto valor nutricional.

Suzi, ou Nano, como é carinhosamente denominada pelo neto cinegrafista, nasceu no Egito, em 1933, e "tem dois objetivos na vida: encher suas geladeiras e a dos seus netos. E basta” (Suzi Parienté, 2018).

Após um breve diálogo ao telefone, no qual o neto anuncia que a encontrará na semana seguinte, o filme inicia com Nano já na cozinha, com avental, touca no cabelo e separando os ingredientes da receita que, dessa vez, será ensinada ao neto. Enquanto se movimenta entre o fogáo e a mesa, a trajetória dessa mulher, nascida em 1933, no Cairo, e ali tendo vivido até 1956, é contada pelo neto, que coloca em primeiro plano a história de seu pai, que tinha a idade de dois anos e meio quando os judeus foram expulsos do Egito em razão da guerra Egito-Israel e da crise do Canal de Suez. As receitas de Nano são, conforme suas palavras, "meu único elo tangível com o Egito... quando ela cozinha, seu sotaque, suas histórias, os ingredientes que utiliza, me fazem viajar a um Cairo imaginário, uma cidade que eu não conheço, mas que, no entanto, me define".

Enquanto deixa que carne e molokheya se convertam em cozido, Nano abre geladeira e freezer e deles retira pratos já prontos e congelados para suprir, tal como parece ser sua grande satisfação, a geladeira do neto. Entre um prato e outro, evoca fragmentos de sua vida, boa parte dela transcorrida no ambiente de uma cozinha doméstica, preparando refeiçóes para a família.

Eu fiz a matric, um exame como o Bac aqui, era sério e se tu tinhas a matric podias entrar na universidade, eu queria fazer pediatria. Mas papai dizia que uma moça não deixa a casa de seus pais e é o pai que decide o que sua filha vai fazer... ela não 
me dá ordens, dizia ele. Eu não fui para a Universidade e casei com 18 anos. (Suzi Parienté, 2018).

Os limites restritos de uma família de tradição religiosa muçulmana aparecem como forma de definição de destinos.

É na cozinha, entretanto, que a livre escolha é exercida plenamente, o que pode ser percebido no uso de pasta de tomates industrializada, "sem colorantes, sem conservantes", como afirma ela mostrando a embalagem ao neto. "E tu acreditas que isso que eles dizem é verdade?", pergunta ele, ao que Nano responde "sim", o sim como uma expressão da liberdade em escolher a pasta de tomate adquirida já pronta "sem conservantes, nem colorantes", mesmo que isso seja apenas um rótulo, e não o método tradicional de prensar os tomates, processo longo e trabalhoso, suprimido por ela como um presente dado a sua velhice.

Nano frita grãos para que "o perfume do coentro saia bem". O coentro vai para a panela com o cozido de molokheya, ao qual acrescenta "dois cubos", dois temperos prontos, outra atualizaçáo pragmática de uma receita tradicional.

O odor que se pode imaginar como resultado dessa infusão parece ser um gatilho memorial para o neto, que conclui a filmagem com Suzi Parienté (2018) colocando-se a si próprio em uma vivência de imigração e estranhamento.

[Jonas Parienté] - Então é isso, eu sou um desraizado. Eu não lhes havia falado mas do lado de minha mãe, minha família é polonesa. Meu tio e minha tia nasceram na URSS durante a Segunda Guerra Mundial, e minha mãe, que nasceu em Paris, aprendeu o Yiddish e o polonês antes de aprender o francês. Eu filmei minha avó para me recordar, por conhecer seus ínfimos ingredientes que me vinculam com as origens de minha família. Receitas de cozinha. Um sotaque que transforma o francês em língua eslava ou árabe. Pedaços fragmentados de narrativas. Então a Molokheya é um pouco de mim. É como um espelho. Eu sou Paris e sou Cairo. Sou árabe e sou Yiddish. Eu filmo para não esquecer. Eu cozinho para transmitir.

\section{Cozinha, memória e narrativa: fragmentos de vida de avós}

A associação entre cozinha, memória e narrativa se apresenta como uma das mais estáveis e evidentes. $\mathrm{O}$ ato de preparar alimentos traz consigo elementos fortemente memoriais, tanto no nível da narrativa quanto do não verbalizado. No plano não verbal, duas modalidades estáo relacionadas com o estudo proposto neste artigo, ambas passando pelo corpo como um vetor da memória. A primeira é aquela que se observa nos gestos, nos movimentos do corpo, derivada de múltiplas aprendizagens 
ao longo da vida, caracterizada pela repetição, internalizada como uma memória de baixo nível, a protomemória, na definição de Joël Candau (2011, 2020), ou memória procedural (Izquierdo et al., 2013). A característica dessa modalidade memorial, além de estar constantemente atuando no plano mais inconsciente e pela repetiçáo, é sua forte capacidade de compartilhamento. Ao observarmos os movimentos que realizam as cozinheiras, em particular as que săo objeto dos vídeos analisados, vemos que são movimentos repetitivos, feitos sem que a evocação desse saber-fazer esteja sendo acionada. Assemelham-se os gestos nas diferentes culturas que cada uma das mulheres traz em si. A essa memória procedural segue-se a memória sensorial, cuja evocação dá-se por associaçáo. "E de súbito a lembrança apareceu", movido pelo gosto da Madeleine mergulhada no chá, Proust se remete à casa da tia em Combray, numa incursáo memorial ativada por um estímulo sensorial: o pequeno bolinho mergulhado no chá. Essa, que poderíamos chamar de memória sensorial, combina elementos da memória olfativa, gustativa, tátil e visual, faculdades imprescindíveis ao ato de executar uma receita e depois repeti-la, buscando sempre recuperar a forma original registrada na memória. Da mesma forma, algumas associaçóes sensoriais levam a associaçóes semânticas (Deroy, 2013), como representaçóes verbalizadas pelos netos associando o perfume e imagem da comida com a memória, ou mesmo "o Kneidler como passaporte askhenazi", e "o Cairo que não conheço", como expressões de identidades informadas pela comida.

No plano da narrativa oral propriamente dita, esta se forja no ato de executar as receitas. É preparando os legumes que Julia evoca sua trajetória marcada pela deportação e vida no campo de concentração; é pela execução da receita tradicional egípcia que Nano fala de sua vida, da interdição em seguir estudos, da proibição de trabalhar fora de casa, imposta pelo marido. Também, é enrolando as folhas de videira que Rosa faz alusão à proeminência do masculino na cultura árabe, ou a referência às dificuldades de transmissáo para a filha dos saberes culinários associados ao Marrocos, na cozinha de Ninette. As trajetórias de vida aparecem em fragmentos densos através dos quais se pode depreender informaçóes dos contextos aos quais estão atrelados.

O fio condutor dessas imersôes memoriais são as receitas, todas elas associadas às histórias biográficas dessas mulheres e de seus netos. Através das receitas, vai-se dando a perceber os quadros sociais, como espaço, tempo, rituais, família, religiáo, bem como o encontro entre duas geraçóes - das avós e dos netos. Analisando práticas culinárias na Itália, Fortunati (2015) observa que as receitas podem ser vistas como um objeto cultural, no sentido de refletirem formas de relação com a comida e o comer que se estruturam dentro da cultura propriamente dita, mas, também, como instrumentos heurísticos para analisar as condiçóes de vida das mulheres, o trabalho doméstico, as formas de fazer e as permanências e rupturas que ocorrem no tempo. Ao mesmo tempo, as receitas, tal como aparecem no projeto Grandmas, "permitem construir pontos de ancoragem de identidades imaginárias que atenuam os efeitos do desenraizamento". 
(Sherman, 2017, p. 3). Articulando diferentes temporalidades, as receitas executadas podem ser compreendidas como evocadores, apoios para a memória, reminding, categoria empregada por Paul Ricoeur com base nos "três modos mnemônicos" de Edward Casey, e que, tal como afirma Ricoeur, náo há modo melhor de defini-la que associando-a ao termo recordar: "isso me faz recordar aquilo, me faz pensar naquilo outro" (Ricoeur, 2000, p. 46).

Como num movimento paralelo ao sentido identitário ou mesmo nostálgico da receita, estão as adaptaçōes, modificações, cujo objetivo é torná-las mais práticas, simplificadas, menos exaustivas numa fase da vida na qual já não existe a obrigatoriedade cotidiana de cozinhar. No tempo da aposentadoria, do envelhecimento do corpo e da premência por viver o que ainda se tem a viver, cozinhar por opção, desonerando-se dos esforços do passado, é um ato de autonomia e libertação. Falas como as de Julia, dizendo que faz mais de três anos que não prepara a receita, ou de Suzanne, afirmando que cozinhar nunca foi seu forte, ou mesmo de Ninette, abdicando dos sabores do passado em nome do direito de não ter que ir para a cozinha, são expressóes dessa espécie de resistência interior, o direito a viver como se decide viver.

\section{Cozinhando a várias mãos...}

A inspiração para este artigo, o Grandmas Project, possibilitou experenciar o acesso às narrativas de vida de mulheres idosas a partir de um percurso metodológico diferente do que usualmente se faz quando em situação do encontro entre pesquisadora e entrevistado. Na experiência gastronômica que envolve o programa, várias categorias de análise são identificadas, possibilitando transformar cada vídeo em uma incursão em dois universos, o das avós, em suas narrativas, e o dos netos, em sua experiência memorial e afetiva.

A figura dos netos aparece, nesse contexto do Grandmas, como um dos polos de um encontro intergeracional que reforça a ideia de que são eles, e não a segunda geração, os que acabam cumprindo um papel fundamental de empreendedores da memória (Michel, 2010), engajados em buscas memoriais relacionadas a processos identitários e de relação com o passado.

Ainda que o Grandmas Project não se apresente como um projeto fundado no método de História Oral, a forma como se organiza, em termos de abordagem e das possibilidades que deixa a perceber na relação sujeito e quadros históricos e sociais que fazem perceber em sua trajetória, nos autoriza a defendê-lo como um exemplo de aplicação dessa metodologia. Para tanto, nos amparamos em Michael Frisch (2016a), em seu profundo questionamento aos limites e paradoxos que envolvem a História Oral, dentre os quais um uso muito restritivo da entrevista, abordando-a como um fato que se encerra nela própria, o paradoxo da oralidade que, embora esteja no centro 
da própria existência e seja justificativa do método pela entrevista realizada, acaba se transformando numa espécie de arquivo secundário ou acessório, o "segredo escuro e profundo" que designa a forma contraditória de nossa relaçáo com o momento em que estabelecemos uma relaçáo de escuta com aquele que fala. Ainda, e como outro paradoxo que nos aponta o autor, colocamo-nos diante do que ele aborda como "direçáo" ou "afunilamento essencialmente linear", etapa que pressupóe uma decupagem do material bruto resultante da entrevista, uma espécie de triagem que, conforme nossos objetivos iniciais, dá conta de separar o que será ou náo incluído no texto destinado a ser o documento público.

Em resposta a esses paradoxos, que podem ser analisados como vulnerabilidades do método, ou mesmo como espécie de habitus do ofício, comportamentos internalizados que passam a compor nosso repertório de açóes, Frisch nos aponta outras possíveis formas de explorar as inúmeras possibilidades que nos traz a "era digital", no sentido de propor a entrevista como um espaço fortemente aberto, ampliando ao máximo o que nos traduz como a "sensibilidade pós-documental", que leva a pensar em um produto final que, todavia, pode ser constantemente explorado, que gera pistas, que não se traduz apenas pelos descritores os quais, como tradutores de uma entrevista, nos autorizamos a estabelecer.

"Explorar", mais do que "buscar", eis a fórmula que nos aponta Frisch (2016b) como um dos horizontes que nos abrem as novas (e nem táo novas) ferramentas virtuais de extroversão do que fazemos, permitindo encontros de subjetividades e afetividades, indo além do "cru e do cozido", formulaçáo perfeita que nos permite sair da entrevista formal e avançar para "a bagunça na cozinha", expressáo utilizada pelo autor para designar essa ampliação do documento oral como um espaço de interação dos usuários. Explorar, vasculhar, entrar no "espaço íntimo" da entrevista: são movimentos que se colocam em perfeito acordo no ato de filmar as avós, nos 8 minutos nos quais "a cozinha digital" de Michael Frisch se materializa numa cozinha real na qual, como uma expressão viva da "autoridade compartilhada" do autor, juntos cozinham quem filma e quem é filmado, misturam-se mãos amassando os alimentos, compartilhamse os odores do cozimento, combinam-se temperos e utensílios e, ao final, degusta-se o prato saborosamente concebido neste processo de "bricolagem", no qual diferentes atores e vozes constroem um produto. Nesse processo, as distinçóes entre quem escuta e quem narra se apresentam tênues, quase imperceptíveis. As evocaçóes à memória partem de diferentes apelos, ora da observação sobre o cabelo feita pela neta, que leva a avó a uma incursão por um passado difícil vivido num campo de concentração, ora da constataçáo, feita por outra avó diante dos bolinhos de damasco, de que raras vezes havia executado tal receita de tradição judaica para os filhos.

Podemos aplicar, ao encontro proposto no Grandmas Project, as ideias de Frisch e, ainda, propor certo deslizamento de nossa compreensão do método de História Oral, buscando situá-lo dentro destas novas formas comunicacionais e mesmo de 
contingenciamentos que levaram à adoção de "novos modos perceptivos e cognitivos ativados na produção de entrevistas online", como bem afirmam Santhiago e Magalhães (2020), face aos limites e às restriçóes impostas por uma conjuntura de pandemia e consequente isolamento social. Não dispomos do encontro entre dois corpos, náo podemos aferir expressóes e emoçóes pelos gestos e olhares, entretanto, podemos, apurando a ideia de "autoridade compartilhada" e de sensibilidade frente ao outro, transformar o espaço "frio" em "quente”, livre utilização da expressão criada por Serge Barcellini. ${ }^{18}$

Finalmente, Grandmas Project nos leva a refletir como aparece representada a velhice em nossas sociedades contemporâneas, ora medicalizada para evitar o processo natural da ação do tempo no corpo, ora edulcorada com novas categorias semânticas para defini-la, ora como um problema social, raramente como uma possibilidade de aprendizado e transmissão de conhecimentos. É essa última perspectiva que conduziu a elaboração do Grandmas Project, e, posto que a vida é dinâmica, assim como a memória, hoje já se converteu, ele próprio, em um reminder daquelas avós que agora sobrevivem na lembrança.

\section{Referências}

ACHACHE-WIZNITZER, Suzanne. Souvenirs: les fragments d'un puzzle. Annales ESC, n. 3, p. 667-671, 1993.

BERGSON, Henri. Essais sur les donnés immédiates de la conscience. Paris: PUF, 2011.

BERQUÓ, Elza; BAENINGER, Rosana. Os idosos no Brasil: considerações demográficas. Campinas: Unicamp, Núcleo de Estudos de População, 2000. (Textos Nepo, 36).

BORDIN, Luisa. Intervista ad Alessandro Casellato. Quaderni dela Rete delle GeoStorie, n. 1, p. $14-22,2020$.

BOURSIER, Jean-Yves (Org.). Musées de guerre et mémoriaux. Paris: Éditions de la Maison des sciences de l'homme, 2005.

CABREIRA, Marcia Maria. Cultura e identidade em São Paulo: a imigração síria e libanesa. EccoS Revista Cientifica, São Paulo, v. 3 n. 1, p. 93-103, 2001.

CANDAU, Joël. Memória e identidade. São Paulo: Contexto, 2011.

CANDAU, Joël. Memória ou metamemória das origens? Caderno de Letras, Pelotas, n. 37,

18 O autor refere-se a espaços expográficos erigidos em lugares que sediaram eventos traumáticos (o quente) e os que são construídos para falar de tais eventos (o frio). Tais expressões estão presentes na entrevista concedida por ele à Marie-Hélène Joly, em 8 de janeiro de 1996 e citada por Jean-Yves Boursier (2005, p. 12). 
p. 11-30, maio/ago. 2020. Disponível em: https://periodicos.ufpel.edu.br/ojs2/index.php/ cadernodeletras/article/view/19531. Acesso em: 22 maio 2021.

CANDAU, Joël; FERREIRA, Maria L. Mémoire et patrimoine: des récits et des affordances du patrimoine. Educar em Revista, Curitiba, n. 58, p. 21-56, 2015. Disponível em: https:/www. scielo.br/scielo.php?script=sci_arttext\&pid=S0104-40602015000400021. Acesso em: 22 maio 2021.

CARADEC, Vincent. Vieillir au grand âge. Recherche en Soins Infirmiers, v. 3, n. 94, p. 2841, 2008. Disponível em: https://www.cairn.info/revue-recherche-en-soins-infirmiers-2008-3page-28.htm. Acesso em: 22 maio 2021.

CERTEAU, Michel de. A invenção do cotidiano: 2. morar, cozinhar. Petrópolis: Vozes, 1996.

DEROY, Ophelia. Contre l'oubli des sens: associations sensorielles et reconstruction mémorielle In: PESCHANSKI, Denis; MARÉCHAL, Denis (Org.). Les chantiers de la mémoire. Paris: INA Éditions, 2013. p. 82-83.

FORTUNATI, Leopoldina. The recipe: the queen of pragmatics. An Italian case study. ESSACHESS - Journal for Communication Studies, v. 8, n. 2, p. 27-48, 2015.

FRISCH, Michael. A história pública não é uma via de mão única, ou, De $A$ Shared Authority à cozinha digital, e vice versa. In: MAUAD, Ana Maria; ALMEIDA, Juniele Rabêlo de; SANTHIAGO, Ricardo. História pública no Brasil: sentidos e itinerários. Sáo Paulo: Letra e Voz, 2016b. p. 57-70.

FRISCH, Michael. Oral History in the digital age: beyond the raw and the cooked. Australian Historical Studies, v. 1, n. 47, p. 92-107, 2016a.

JOUTARD, Philippe. L'oral comme objet de recherche en histoire. Bulletin de l'AFAS - Sonorité, n. 28-29, p. 49-56, 1992. Disponível em: http://journals.openedition.org/afas/2683. Acesso em: 31 maio 2021.

JOUTARD, Philippe; GRANET-ABISSET, Anne-Marie. Histoires de vie, histoire dans la vie. Philippe Joutard et l'histoire orale à la française. Entretiens des 4 octobre et 12 décembre 2012. Sociétés \& Représentations, n. 35, p. 183-207, 2013. Disponível em: https://www.cairn. info/revue-societes-et-representations-2013-1-page-183.htm. Acesso em: 31 maio 2021.

HALBWACHS, Maurice [1950]. La mémoire collective. Paris: Albin Michel, 1997.

IZQUIERDO, Iván Antonio; MYSKIW, Jociane de Carvalho, BENETTI, Fernando, FURINI, Cristiane Regina Guerino. Memória: tipos e mecanismos - achados recentes. Revista USP, São Paulo, n. 98, p. 9-16, 2013.

MAUGER, Gérard. “La jeunesse n'est qu'un mot”. A propos d'un entretien avec Pierre Bourdieu. Agora débats/jeunesses, n. 26, p. 137-142, 2001.

MEAH, Angela; JACKSON, Peter. Re-imagining the kitchen as a site of memory. Social \& Cultural Geography, v. 17, n. 4, p. 511-532, 2016.

MICHEL, Johann. Gouverner les mémoire: les politiques mémorielles en France. Paris: PUF, 2010.

MUXEL, Anne. Individu et mémoire familiale. Paris: Nathan, 1996.

PORTELLI, Alessandro. História Oral e poder. Mnemosine, v. 6, n. 2, p. 2-13, 2010. 
RICOEUR, Paul. La mémoire, l'histoire, l'oubli. Paris: Seuil, 2000.

SANTHIAGO, Ricardo; MAGALHÂES, Valéria Barbosa de. Rompendo o isolamento: reflexões sobre história oral e entrevistas à distância. Anos 90, Porto Alegre, v. 27, 2020.

SHERMAN, Virginia Allen-Terry. Les traditions culinaires: ancrage ou libération culturelle? Une étude des memoires culinaires. ILCEA, n. 28, 2017. Disponível em: http://journals.openedition. org/ilcea/4165. Acesso em: 31 maio 2021.

TRUZZI, Oswaldo. Patrícios: sírios e libaneses em São Paulo. São Paulo: Hucitec, 1997.

TRUZZI, Oswaldo. Redes em processos migratórios. Tempo Social, São Paulo, v. 20, n. 1, p. 199-218, 2008.

\section{Fontes Orais}

ACHACHE-WIZNITZER, Suzanne (Mamé) [87 anos]. [2017]. Entrevistadora: Mona Achache, 2016. Depoimento concedido ao programa Grandmas Project. Disponível em: http:// grandmasproject.org/films/marillenknodel/. Acesso em: 7 jun. 2021.

DEBEAUVAIS, Sonia [90 anos]. [2018]. Entrevistadora: Emma Luchini, 2016. Depoimento concedido ao programa Grandmas Project. Disponível em: http://grandmasproject.org/films/ frikkadel/. Acesso em: 7 jun. 2021.

MILAN, Rosa Maluf [97 anos]. [2015]. Entrevistador: Mathias Mangin. São Paulo, SP, 2016. Depoimento concedido ao programa Grandmas Project. Disponível em: http://grandmasproject. org/films/mehchi/. Acesso em: 7 jun. 2021.

PARIENTÉ, Suzi (Nano) [93 anos]. [2018]. Entrevistador: Jonas Parienté, 2016. Depoimento concedido ao programa Grandmas Project. Disponível em: http://grandmasproject.org/films/ molokheya-2/. Acesso em: 7 jun. 2021.

WALLACH, Julia [93 anos]. [2018]. Entrevistadora: Frankie Wallach, 2016. Depoimento concedido ao programa Grandmas Project. Disponível em: http://grandmasproject.org/films/ kneidler/. Acesso em: 7 jun. 2021.

ZAGURY, Ninette. [2018]. Entrevistadora: Elsa Lévy, Paris, FR, 2016. Depoimento concedido ao programa Grandmas Project. Disponível em: http://grandmasproject.org/films/salade-cuite-2/. Acesso em: 7 jun. 2021.

Recebido em 28/02/2021.

Versão final reapresentada em 28/04/2021.

Aprovado em 28/04/2021.

Fonte de financiamento: nada a declarar.

Conflitos de interesse: nada a declarar. 